\title{
Management of Separated Irrigating Needle within Root Canal: A Case Report
}

\author{
Rasheeda Shamshu ${ }^{1}$, Radhakrishnan Nair K ${ }^{2}$, Praveena Geetha ${ }^{3}$, Princy Paul ${ }^{4}$
}

\begin{abstract}
Background: Irrigation is an integral part of successful root canal treatment. Syringe and needle irrigation is an effective method to control microbial flora of the root canal. Needle with multiple vents efficiently delivers irrigating solutions. Geometric configuration of the irrigating needle may predispose it to fracture during irrigation. A fractured needle causes procedural difficulties during treatment. Careful removal of the fragment with minimal tissue loss improves the prognosis of the treatment.

Case description: This case report describes the management of a fractured double-side-vented irrigating needle within the mesiobuccal canal orifice of maxillary first molar. The separated fragment was successfully retrieved with the help of indirect ultrasonics under magnification with a dental operating microscope.

Conclusion: Development in techniques and armamentarium has led to successful retrieval of separated fragment from the root canal. The selection of a suitable method according to the position of the fractured instrument facilitates retrieval with minimal tissue removal.

Keywords: Double-side-vented irrigation needle, Fractured irrigating needle, Magnification, Retrieval, Ultrasonics.

Conservative Dentistry and Endodontic Journal (2020): 10.5005/jp-journals-10048-0054
\end{abstract}

\section{BACKGROUND}

The endodontic treatment depends upon the quality of the cleaning and shaping of the root canals. Syringe irrigation remains a widely used irrigant delivery method. Different irrigation needles with different gauges have been used during root canal treatment. However, the effectiveness varies with the type of the needle. This is due to the ability of the needles to reach the apical third and deliver the solution to the full working length (WL) of the root canal. ${ }^{1}$

Over the years, several types of needles have been used to deliver irrigants into the root canals. ${ }^{2,3}$ These needles mainly differ in the presence of an open or closed tip and one or more outlets. In the past, large needles (21-25G) were commonly employed for irrigant delivery. ${ }^{4}$ Such needles could hardly penetrate beyond the coronal third of the root canal, even in wide root canals. More recently, the use of finer diameter needles (28G, 30G, or 31G) has been advocated, mainly because they can reach farther into the canal, even to WL. ${ }^{5,6}$

Periapical extrusion of irrigating solution has been one of the disadvantages described with the use of needle irrigation. ${ }^{7}$ For this reason, irrigation needles with a side opening have been developed to minimize the risk of extrusion and tissue damage. ${ }^{8}$ Studies have reported that side-vented closed-end needles were more efficient than conventional needles in the removal of debris from the root canal. Extreme pressure during irrigation or binding of the irrigation needle tip in the root canal may predispose the irrigating needle to fracture within the canal especially for a side-vented needle. Also, the hollow design of irrigating needles makes them easy to fracture.

During irrigation of the root canal, the risk of fracture of the needle may occur due to the geometrical configuration of the needle. The presence of a fractured segment can affect the proper disinfection and obturation of the root canal system (RCS). This can, in turn, affect the long-term prognosis of the tooth. Strindberg reported a $19 \%$ reduction in the rate of healing of apical tissues when separated instruments were present. ${ }^{9}$

\begin{abstract}
${ }^{1-4}$ Department of Conservative Dentistry and Endodontics, Azeezia College of Dental Sciences and Research, Kollam, Thiruvananthapuram, Kerala, India
\end{abstract}

Corresponding Author: Rasheeda Shamshu, Department of Conservative Dentistry and Endodontics, Azeezia College of Dental Sciences and Research, Kollam, Thiruvananthapuram, Kerala, India, Phone: +91 8086323609, e-mail: rasheedashamshu92@gmail.com

How to cite this article: Shamshu R, Radhakrishnan Nair K, Geetha P, et al. Management of Separated Irrigating Needle within Root Canal: A Case Report. Cons Dent Endod J 2020;5(1):19-22.

Source of support: Nil

Conflict of interest: None

Once it is fractured, decision has to be made whether to retrieve the fragment or to leave it as such and complete the treatment. Several complicating factors have to be considered while planning the treatment options for removal of the fractured segment from the root canals. They are the anatomy of the RCS; the devices available to remove the fragment; the experience and ability of the professional to solve the problem; the localization, size, position, and diameter of the fractured segment. ${ }^{10}$

Management of separated fragment includes (a) removal of the separated fragment, (b) bypassing the broken fragment, and (c) obturating at the level of separated fragment. ${ }^{11}$ Various techniques have been suggested to retrieve the separated fragment which includes ultrasonic technique, Masserann kit, and instrument removal system. Studies have shown that use of ultrasonics with magnification has led to high success rate of retrieval of the separated instrument. ${ }^{12}$

Careful manipulation of needle during irrigation is important especially when irrigating thin roots like mesiobuccal root of maxillary molar. This report describes a case in which ultrasonic technique was used to remove a fractured irrigating needle from the mesiobuccal canal of upper maxillary molar under magnification. 


\section{Case Description}

A 56-year-old male patient reported to the department with a complaint of pain in relation to 26 since 2 weeks. The tooth was restored 1 year back and had severe spontaneous pain, and the tooth was tender on percussion. It was a case of symptomatic apical periodontitis, and root canal treatment was initiated immediately. Under local anesthesia and rubber dam isolation, the permanent restoration was removed and the pulp chamber was accessed, and the four canals, MB1, MB2, DB, and P canals, were located. During biomechanical preparation, a double-side-vented 30G needle was used for irrigation. Toward the end of preparation, during withdrawal of the irrigating needle, it had some resistance and a 4 $\mathrm{mm}$ tip of the irrigating needle got fractured at the notched area within the MB canal at the coronal third. On X-ray evaluation, the fracture of the tip of the irrigating needle was confirmed coronally (Figs 1 and 2). The fracture had occurred at the coronal part of the root canal, and an attempt was made to remove the fragment. Under magnification, the fractured tip of the needle was found projecting at the MB1 orifice of the root canal (Fig. 3). Before attempting removal of the fragment, the other three orifices were

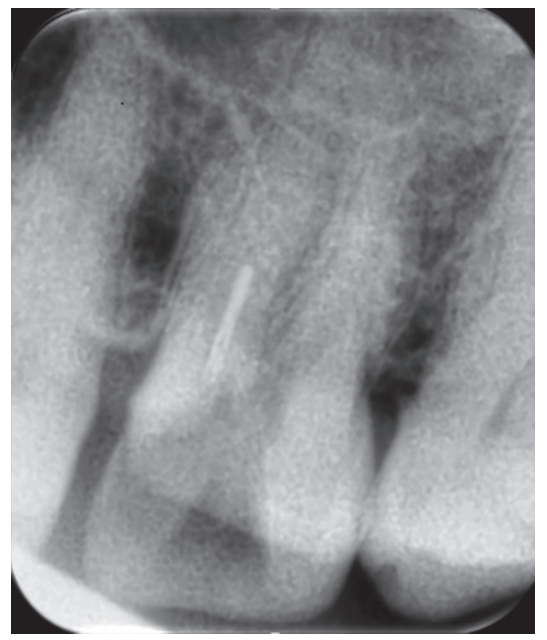

Fig. 1: Radiograph showing $4 \mathrm{~mm}$ separated needle fragment at coronal third of the MB1 root canal

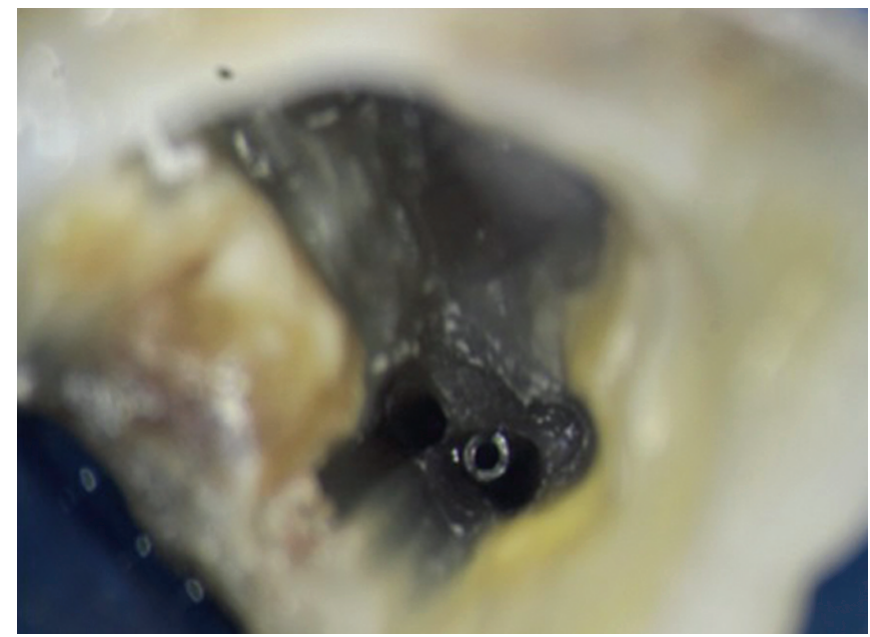

Fig. 3: The fractured tip of the needle projecting from the MB1 orifice of the root canal blocked with Teflon tape so as to prevent accidental spillage of the fractured segment during retrieval. A Steiglitz forcep (Hu-Friedy, $\mathrm{IL}$, USA) was used with minimum coronal pressure to elevate the fragment, but it resisted removal. So, it was decided to use indirect ultrasonic vibration to retrieve the fragment. A DG-16 explorer was placed in contact with the separated fragment in the canal, and a low-grade ultrasonic energy was applied to the explorer with ultrasonic scaler tip. This procedure completely loosened the needle fragment and vibrated out of the orifice and then it was grasped with a tweezer and removed safely (Figs 4 and 5). Radiographic assessment ensured complete retrieval of the fragment with patent canals (Fig. 6). After following irrigation protocol, obturation was done by cold lateral compaction method (Fig. 7). Postendodontic restoration was given, and the patient was reviewed after 3 months following which full-coverage restoration was given (Fig. 8).

\section{Discussion}

Irrigant delivery by syringe and needle during root canal treatment dates back more than a century. Despite the development of newer irrigation systems, it is still a recommended method of irrigation. ${ }^{13}$

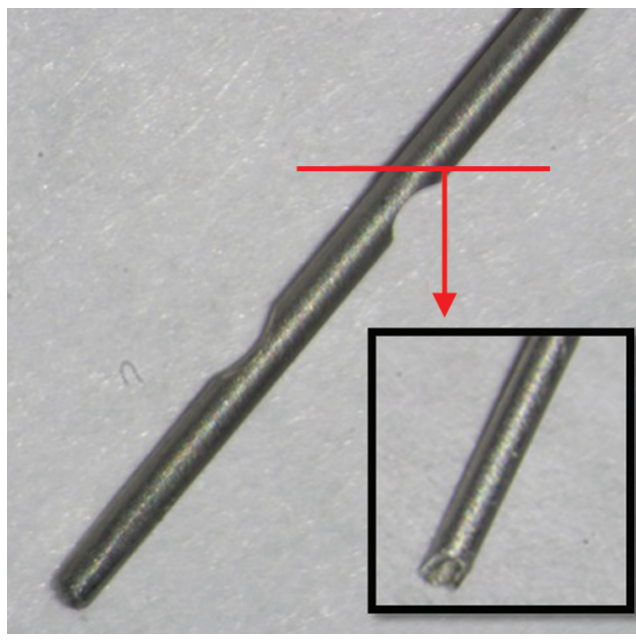

Fig. 2: Photograph showing configuration of double-side-vented needle. Inset: the needle fractured at the notched area

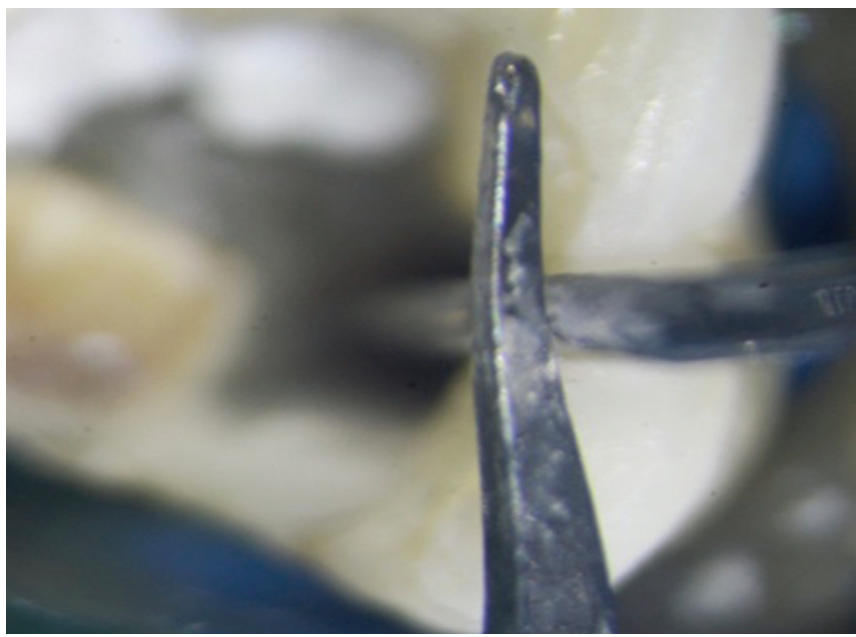

Fig. 4: Indirect ultrasonic vibration-ultrasonic tip placed in contact with DG-16 explorer 


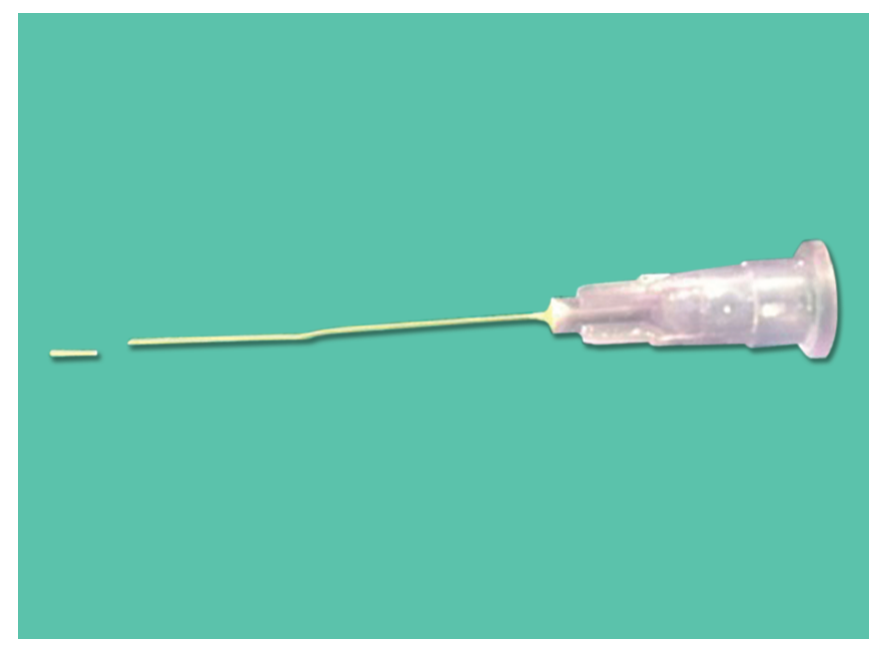

Fig. 5: A fractured irrigating needle along with the retrieved segment

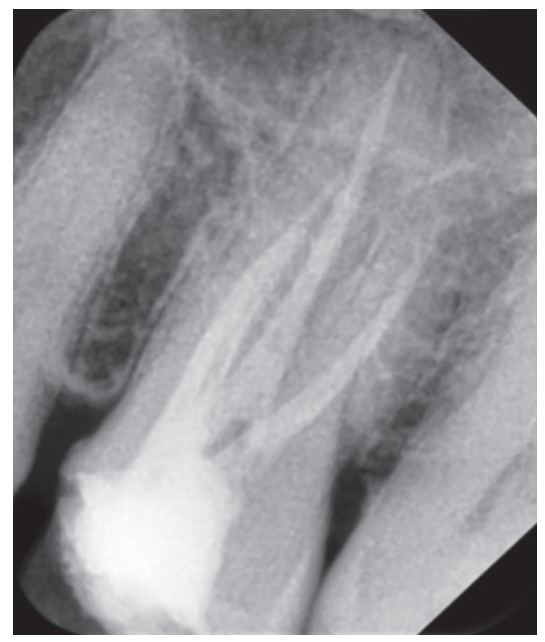

Fig. 7: Immediate postoperative radiograph

One of the advantages of syringe irrigation is that it allows easy control of needle penetration within the canal and the volume of irrigant that is flushed through the canal. ${ }^{2}$

Open-ended tips of the needle express irrigant out the end toward the apex thereby increasing the apical pressure. Furthermore, the beveled tip poses increased possibility of wedging inside the root canal. ${ }^{2}$ Closed-ended needles can be side vented, double-side-vented, and multivented. Closed-ended irrigant tips create more pressure on the walls of the root canal and improve the hydrodynamic activation of irrigant and reduce the chance of apical extrusion. ${ }^{14}$ The double-side-vented needles have two notches at 4 $\mathrm{mm}$ from the tip thereby posing risks of fracture owing to the weak configuration of the needle at that area. During irrigation, a slight tilting or change in the forces can cause fracture of the needle at the notched area. The dentin fragments that remain within the root canal during irrigation can make the irrigating needle tight within the canal, thereby preventing the free effective movement of the needle posing a risk of fracture.

The successful removal of fractured segment relies on factors such as length, type, and position of the segment in relation to canal curvature. The fractured segment can be easily retrieved if it lies in the straightaway portion of the canal and if one-third of

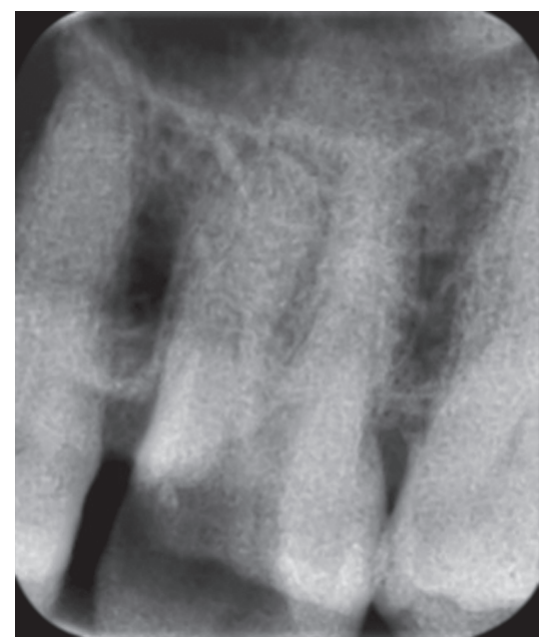

Fig. 6: Radiograph after removal of separated fragment

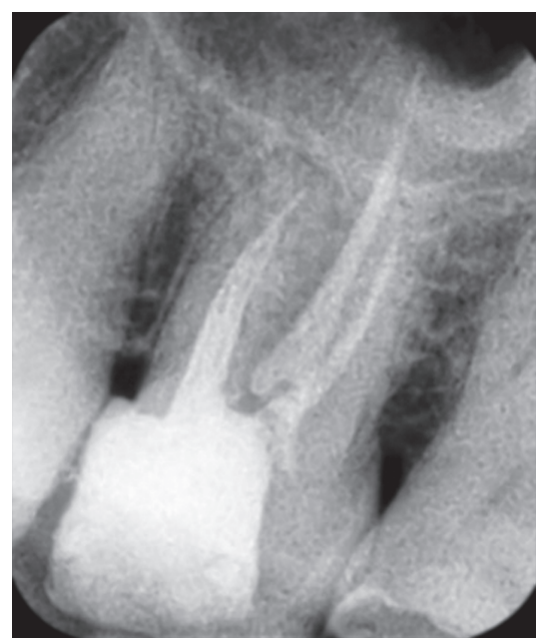

Fig. 8: Postendodontic radiograph review after 3 months

its overall length is exposed in the pulp chamber. If the broken instrument lies apical to canal curvature, then it is usually not possible to retrieve it. According to Nevares et al. when the separated fragment was visible with a dental microscope, there was increased chances of retrieval. ${ }^{15}$ Removal of the fractured fragment also becomes more predictable if a gap between the fragment and root canal walls is present. In the present case, the fragment was visible at the coronal third of the mesiobuccal canal. So, retrieval was attempted as there was good visualization and straight line access.

Ultrasonics, in conjunction with a microscope, is considered the most conservative method of removal of broken fragment. In the direct method, heat is generated due to the friction of ultrasonic tips against canal wall dentin or fractured instrument which may lead to faster instrument fatigue and secondary fracture. ${ }^{16,17}$ In this case, indirect ultrasonics was employed to reduce the amount of root dentin removed and to prevent the chances of secondary fracture of the fractured segment which can further make retrieval difficult. In the above case report, the vibration was transmitted with lower frequency to the fractured needle which helped in its retrieval without further fracture. Use of magnification also contributed to the success of the procedure. 


\section{Conclusion}

The development in technology, advanced armamentarium, and expertise enable successful management of fractured instrument. The indirect ultrasonic technique renders a predictable method of retrieving separated instruments from root canal with minimal loss of dentin. Closed-ended side-vented needles offers efficient irrigation of the root canal and careful manipulation of the needle during irrigation precludes the possibility of needle fracture.

\section{Clinical Significance}

Irrigation is an important step during chemomechanical preparation of the root canal. During irrigation, there is a risk of fracture of the irrigating needle owing to its configuration. With technological advancements in vision and ultrasonic instruments, the fractured segments can be retrieved thereby improving the outcome of root canal treatment.

\section{References}

1. Kahn FH, Rosenberg PA, Gliksberg J. An in vitro evaluation of the irrigating characteristics of ultrasonic and subsonic handpieces and irrigating needles and probes. J Endod 1995;21(5):277-280. DOI: 10.1016/S0099-2399(06)80998-2.

2. Boutsioukis $C$, Verhaagen $B$, Versluis $M$, et al. Evaluation of irrigant flow in the root canal using different needle types by an unsteady computational fluid dynamics model. J Endod 2010;36(5):875-879. DOI: 10.1016/j.joen.2009.12.026.

3. Goldman M, Kronman JH, Goldman LB, et al. New method of irrigation during endodontic treatment. J Endod 1976;2(9):257-260. DOI: 10.1016/S0099-2399(76)80085-4.

4. Teplitsky PE, Chenail BL, Mack B, et al. Endodontic irrigation-a comparison of endosonic and syringe delivery systems. Int Endod J 1987;20(5):233-241. DOI: 10.1111/j.1365-2591.1987.tb00620.x.

5. Bronnec F, Bouillaguet S, Machtou P. Ex vivo assessment of irrigant penetration and renewal during the final irrigation regimen. Int Endod J 2010;43(8):663-672. DOI: 10.1111/j.1365-2591.2010.01723.x.
6. Boutsioukis C, Lambrianidis T, Verhaagen B, et al. The effect of needle insertion depth on the irrigant flow in the root canal: evaluation using an unsteady computational fluid dynamics model. J Endod 2010;36(10):1664-1668. DOI: 10.1016/j.joen.2010.06.023.

7. Zairi A, Lambrianidis T. Accidental extrusion of sodium hypochlorite into the maxillary sinus. Quintessence Int 2008;39(9):745-748.

8. Vinothkumar TS, Kavitha S, Lakshminarayanan L, et al. Influence of irrigating needle-tip designs in removing bacteria inoculated into instrumented root canals measured using single-tube luminometer. J Endod 2007;33(6):746-748. DOI: 10.1016/j.joen.2007.02.013.

9. Strindberg $L$. The dependence of the results of pulp therapy on certain factors: an analytic study based on radiographic and clinical follow up examination. Acta Odontol Scand 1956;14(Suppl 21):1-175.

10. Suter B, Lussi A, Sequeira P. Probability of removing fractured instruments from root canals. Int Endod J 2005;38(2):112-123. DOI: 10.1111/j.1365-2591.2004.00916.x.

11. Saunders JL, Eleazer PD, Zhang P, et al. Effect of a separated instrument on bacterial penetration of obturated root canals. J Endod 2004;30(3):177-179. DOI: 10.1097/00004770-200403000-00012.

12. Madarati AA. Retrieval of multiple separated endodontic instruments using ultrasonic vibration. J Taibah Univ Med Sci 2016;11:268-273. DOI: 10.1016/j.jtumed.2015.11.010.

13. Ingle Jl, Himel VT, Hawrish CE, et al. Endodontic cavity preparation. In: Ingle Jl, Bakland LK. Endodontics. 5th ed., Ontario: BC Decker; 2002. p. 502.

14. Sedgley $C M$, Nagel AC, Hall D, et al. Influence of irrigant needle depth in removing bioluminescent bacteria inoculated into instrumented root canals using real-time imaging in vitro. Int Endod J 2005;38(2):97104. DOI: 10.1111/j.1365-2591.2004.00906.x.

15. Nevares G, Cunha RS, Zuolo ML, et al. Success rates for removing or bypassing fractured instruments: a prospective clinical study. J Endod 2012;38(4):442-444. DOI: 10.1016/j.joen.2011.12.009.

16. Plotino $\mathrm{G}$, Pameijer $\mathrm{CH}$, Grande NM, et al. Ultrasonics in endodontics: a review of the literature. J Endod 2007;33:81-95. DOI: 10.1016/j. joen.2006.10.008.

17. Ward JR, Parashos P, Messer HH. Evaluation of an ultrasonic technique to remove fractured rotary nickel-titanium endodontic instruments from root canals: an experimental study. J Endod 2003;29(11):756-763. DOI: 10.1097/00004770-200311000-00017. 